RUNNING HEAD: Poverty, gender, and school dropout

Poverty moderates the association between gender and school dropout in South African adolescents

\author{
Mark E Boyes ${ }^{1,2}$, Valeska Berg ${ }^{3}$, \& Lucie D Cluver ${ }^{2,4}$
}

1: School of Psychology and Speech Pathology, Faculty of Health Sciences, Curtin University, GPO Box U1987, Perth, Western Australia, 6845

2: Centre for Evidence-Based Intervention, Department of Social Policy and Intervention, University of Oxford, 32 Wellington Square, Oxford, United Kingdom, OX12ER

3: Faculty of Psychology and Neuroscience, Maastricht University, PO Box 616, MD Maastricht, 6200

4: Department of Psychiatry and Mental Health, University of Cape Town

\title{
Citation:
}

Boyes, M. E., Berg, V. \& Cluver, L. D. (in press). Poverty moderates the association between gender and school dropout in South African adolescents. Vulnerable Children and Youth Studies. DOI: 10.1080/17450128.2017.1308613.

NOTICE: this is the author's version of a work that was accepted for publication in Vulnerable Children and Youth Studies. Changes resulting from the publishing process, such as peer review, editing, corrections, structural formatting, and other quality control mechanisms may not be reflected in this document. Changes may have been made to this work since it was submitted for publication. A definitive version was subsequently published in Vulnerable Children and Youth Studies, DOI: 10.1080/17450128.2017.1308613. 


\begin{abstract}
This study examined prospective associations between poverty, gender, and school dropout in a large community sample of South African adolescents (Baseline: $n=3515$, Follow-up: $n=$ 3401, 57\% female, age range at baseline: $10-17$ years, mean age at baseline $=13.45)$. School dropout was defined as being enrolled in school at baseline assessment but no longer enrolled in school at follow-up assessment. Poverty was measured at baseline assessment using an index of access to the eight highest socially-perceived necessities for South African children and adolescents. Demographic characteristics including child gender and age, province, and urban versus rural location were recorded at baseline assessment and controlled for in the analysis. As predicted, higher poverty scores $(\mathrm{AOR}=2.01, p<.001)$ were associated with increased odds of school dropout one year later. Gender was not a significant predictor of school dropout (AOR = $1.56, p=.07)$ but did interact with poverty $(\mathrm{AOR}=0.66, p=.04)$ in predicting school dropout. However, our initial hypothesis that the impact of poverty on school dropout would be stronger for girls than boys was not supported. Instead, results indicated that while girls were at elevated risk of school dropout at low and mean levels of poverty, at high levels of poverty this gender difference was no longer evident. Findings suggest that vulnerable boys should not be neglected in policies to improve retention in education in contexts of extreme poverty.
\end{abstract}

Keywords: Education, Poverty, Gender, South Africa 
Poverty, gender, and school dropout 3

Education is a human right. It is globally recognised as an indicator of human development and child wellbeing that opens up new life opportunities and promotes personal and economic growth (Anand \& Sen, 2000). Indeed, ensuring inclusive and equitable quality education and promoting lifelong learning opportunities for all is clearly articulated as one of the United Nations Sustainable Development Goals (United Nations, 2015). However, although viewed as an important human right, in Low and Middle Income Countries (LMIC) leaving school early remains a problem (Lewin, 2007). Poverty and female gender have been identified as important predictors of poor educational outcomes in many sub-Saharan African countries (Lewin, 2007; Nelson Mandela Foundation, 2005). The current research examines prospective associations between poverty, gender, and school dropout in a large community sample of South African adolescents from two provinces (Western Cape and Mpumalanga).

\section{Education in South Africa}

Since the democratic elections of 1994 education has been a priority area for expansion and reform in South Africa (Spaull, 2012). Underlying this focus on education is a recognition of the need to address past inequalities and establish a more flexible, responsive and diverse system of education provision (Sayed et al., 2007). In general, school enrolment rates in South Africa are high by the standards of sub-Saharan Africa (Sayed et al., 2007). At the time the current study was conducted, nearly $99 \%$ of 7-15 year olds (the compulsory school going age) were enrolled in school and approximately $96 \%$ of 7-18 year olds were in school (Meny-Gibert \& Russell, 2010). However, despite these high overall enrolment rates only $44 \%$ of students completed their final year of high school (Department of Education, 2009). Dropout rates are highest during secondary school, leaving students with decreased chances of future employment and earning prospects (Branson \& Leibbrandt, 2013; Meny-Gibert \& Russell, 2010). Additionally, substantial inequalities between historically advantaged and disadvantaged schools remain (Spaull, 2012); with socio-economically disadvantaged schools (in formerly Black areas under 
Poverty, gender, and school dropout 4

Apartheid) performing poorly on tests of numeracy and literacy (Dolata et al., 2010; Howie et al., 2008) and characterised by high rates of grade repetition, school dropout, and teacher absenteeism (Fleisch, 2008; Spaull, 2012; Taylor, Muller, \& Vinjevold, 2003).

\section{Poverty and Education}

There is consistent evidence that poverty is associated with poor educational outcomes (BattinPearson et al., 2000; van der Berg, 2005). Specifically, in South Africa poverty has been associated with elevated risk of school dropout and grade failure (Fleisch, Shindler, \& Perry, 2012; Flisher, Townsend, Chikobvu, Lombard, \& King, 2010; Orkin, Boyes, Cluver, \& Zhang, 2014; Watkins, Sello, Cluver, Kaplan, \& Boyes, 2014). It has been argued that the inability to afford school necessities (e.g. school fees, uniforms, shoes) may lead to school non-attendance and dropout (Fleisch \& Woolman, 2004). Additionally, it has been suggested that girls are more likely than boys to be withdrawn from school in circumstances of family poverty, in order to earn money to supplement family income and/or provide care for dependent family members (Flisher et al., 2010; Gow \& Desmond, 2007). It has also been argued that families living in poverty are on average larger (Maharaj, Kaufman, \& Richter, 2000), and that larger families may have more difficulties allocating resources for each child; thereby elevating risk for poor educational outcomes such as school dropout. Importantly, poor educational outcomes while living in poverty can represent a vicious cycle, as education can be a potential path out of poverty (USAID, 2015). However, if children and adolescents who drop out of school lack literacy and numeracy abilities, this can maintain economic inactivity (Lam, Ardington, \& Leibbrandt, 2011; Modisaotsile, 2012).

\section{Gender and Education}

Regarding gender, there is evidence that in LMIC girls are more vulnerable to school dropout than boys (Herz \& Sperling, 2004; UNESCO, 2012; World Bank, 2016). Accordingly, 
Poverty, gender, and school dropout 5

international policy makers have placed a strong emphasis on reducing gender inequality in education, as educating girls is viewed as a means of improving overall wellbeing and health of families (Herz \& Sperling, 2004; Klasen, 2002; Stacki \& Baily, 2015; USAID, 2015).

Specifically, it is argued that it is essential to provide girls with access to school in order to empower them and increase their opportunities to earn money and break cycles of poverty, which in turn would influence the next generations (Glewwe \& Kremer, 2006; Herz \& Sperling, 2004; Klasen, 2002). For these reasons, eliminating gender disparity at all levels of education is a key focus of the Sustainable Development Goals (United Nations, 2015). However, contrasting findings have also been reported. For example, Lewin (2007) reported that in some parts of Africa (e.g. Ghana, Gambia, and Malawi) more girls than boys are enrolled in secondary school. Additionally, in analyses of South African data by Orkin and colleagues (2014), gender was not associated with school dropout in models adjusting for poverty.

\section{The Current Study}

Given equivocal findings regarding gender, there is a clear need to further understand relationships between gender and school drop out in LMIC. In particular, variability in findings regarding gender differences raises the possibility that associations between gender and school dropout may be moderated by other factors. Given that according to the World Bank (2016) poverty is one of the most important factors determining whether a girl will access an education, and the argument that girls are more likely than boys to be withdrawn from school in circumstances of family poverty (Flisher et al., 2010; Gow \& Desmond, 2007), research examining if poverty and gender interact in predicting school dropout is clearly warranted. The current study aimed to examine prospective associations between poverty, gender, and school dropout (measured one year later) in a large community sample of adolescents from poor South African communities. It was hypothesized that: 1) poverty and female gender would both be prospectively associated with school dropout, and 2) that poverty would moderate the 
Poverty, gender, and school dropout 6

association between gender and school dropout, such that the predicted association between female gender and school dropout would be exacerbated at high levels of poverty.

\section{Method}

\section{Participants}

Adolescents $(n=3515)$ recruited from rural and urban sites in two South African provinces (Western Cape and Mpumalanga) took part in a community-based survey. As part of a larger study of the impacts of familial HIV/AIDS (Cluver et al., 2013), participants were recruited using stratified random sampling of census enumeration areas in four health districts with over $30 \%$ antenatal HIV-prevalence. In both provinces the areas from which participants were sampled are extremely poor. On average households were lacking nearly three of the eight basic necessities identified in the South African Social Attitudes Survey as being a basic need for all children and adolescents in South Africa (see measures section for a description of these necessities). All households in randomly selected enumeration areas were sampled consecutively (door-to-door) and one child per household participated in the study (if there were multiple children in the household one child was randomly selected to participate). Participants were followed up after one year $(n=3401,97 \%$ retention rate). Fifty-seven percent of the sample were female and ages ranged between 10 and 17 years at baseline assessment $(M=$ $13.45, S D=2.15)$. Sample characteristics for both baseline and follow-up assessments are summarised in Table 1.

(Table 1)

\section{Measures}

School dropout: School dropout was defined as being enrolled in school at baseline assessment but no longer enrolled in school at follow-up assessment. Children indicated their 
school enrolment status using a binary response option ( 0 : Not enrolled; 1 : Enrolled) at both the baseline and follow-up assessments. In order to prevent participants who had graduated high school being coded into the dropout category, individuals who were in Year 12 (the final year of high school, $n=27$ ) at baseline assessment were excluded from the analyses.

Poverty: Household poverty was assessed at baseline using an index of access to the eight highest socially-perceived necessities for South African children and adolescents. These items were identified through focus groups (Barnes \& Wright, 2012) and then corroborated by over $80 \%$ of those sampled in the nationally representative South African Social Attitudes Survey (Pillay, Roberts, \& Rule, 2006). The eight items included: a visit to the doctor when needed, medicines when needed, more than one pair of shoes, three meals per day, soap to wash every day, enough clothes to remain warm and dry, school uniform, and money for school fees. Items were reverse-scored ( 0 : Has access to the necessity; 1 : Does not have access to the necessity) and summed to give a total poverty score (total number of necessities lacking).

Demographic characteristics: Demographic characteristics including child gender and age, province, and urban versus rural location were also recorded at baseline assessment.

\section{Procedure}

Ethical approvals were obtained from the University of Oxford, University of Cape Town, and University of KwaZulu-Natal, as well as government Health and Education Departments of the Western Cape, Mpumalanga, and KwaZulu-Natal. Prior to participation, both children and primary caregivers provided voluntary informed consent $(<2.5 \%$ refusal $)$. Participants in the Western Cape spoke isiXhosa and participants in Mpumalanga spoke Sesotho, Xitsonga, or SiSwati. All measures were translated into local languages and translations were checked by back-translation. Children and adolescents participated in the language of their choice. At both assessment points, measures were administered verbally by trained research assistants who had previous experience working with vulnerable children. The 
overall questionnaire package was designed in the style of a teen magazine and included pictures of popular music and television stars. In total, participation took approximately 60 minutes at both baseline and follow-up assessments. No incentive for participation was provided, although participants received certificates of thanks. Confidentiality was maintained unless participants requested assistance or were at significant risk of harm.

\section{Analyses}

Analyses were conducted in three stages in SPSS 23. First, we checked for any differences in age, gender, poverty, and school enrolment (at baseline assessment) between participants lost and retained at follow-up using the full sample. After conducting these initial analyses, the sample was limited to participants enrolled in school at baseline assessment (additionally excluding participants who were in their final year of secondary school at baseline assessment). Second, using this limited dataset we examined descriptive statistics and conducted univariate analyses assessing prospective associations between gender, poverty, and school dropout. Finally, a logistic regression was conducted to test multivariate associations between gender, poverty, and school dropout (controlling for child age, province, and urban versus rural location). The gender*poverty interaction term was included in this model to test whether the association between gender and school dropout was moderated by poverty.

\section{Results}

\section{Children lost and retained at follow-up assessment}

Children and adolescents lost to follow-up did not differ with regard to gender $\left[\chi^{2}(1)=.07, p=\right.$ .79] or school enrolment $\left[\chi^{2}(1)=2.34, p=.13\right]$ at baseline assessment (Table 2). However, participants lost to follow-up were older $[F(1,3512)=6.44, p=.01$, Cohen's $d=0.24]$ and missing more basic necessities $[F(1,3514)=21.55, p<.001$, Cohen's $d=0.36]$. Although a 
one-year follow-up rate of $97 \%$ after is very good, it should be noted that some of the most vulnerable participants could not be traced. The results should be interpreted with this in mind. The sample was limited to youth assessed at both time points for all further analyses $(n=3401)$. (Table 2)

Univariate associations between gender, poverty, and school dropout

Descriptive statistics disaggregated by gender are presented in Table 3. As we were specifically interested in school dropout, the sample was additionally limited to those who were enrolled in school at baseline assessment and not in their final year of secondary school $(n=3319)$. Boys and girls did not differ significantly on poverty scores at baseline assessment; however, a small but significant gender difference was evident at follow-up assessment, with girls reporting significantly higher poverty scores than boys $[F(1,3317)=7.20, p=.007$, Cohen's $D=.09]$. Higher poverty scores were prospectively associated with risk of school dropout. In comparison with children who were still enrolled at school $(M=2.65, S D=2.31)$, children who had dropped out of school by follow-up assessment $(M=4.53, S D=2.17)$ had significantly higher poverty scores at baseline assessment $[F(1,3344)=27.30, p<.001$, Cohen's $D=0.83]$. There was no gender difference in school dropout over the one year follow-up period $\left[\chi^{2}(1)=1.91, p=.168\right]$.

\section{(Table 3)}

\section{Multivariate associations between gender, poverty, and school dropout}

Multivariate associations between gender, poverty (predictors), and school dropout (outcome) were tested in a binary logistic regression model. Given that province $(r=-.41, p<.001)$ and urban versus rural location $(r=.17, p<.001)$ were significantly associated with poverty, and that child age was significantly associated with school dropout $(r=.15, p<.001)$, these were controlled for in the analysis. As one of the primary aims of the study was to examine the 
Poverty, gender, and school dropout 10

potential moderating effect of gender on the association between poverty and school dropout, all predictor variables and covariates entered in the logistic regression model were standardised.

The overall model was significant $\left[\chi^{2}(6)=96.58, p<.001\right]$ and accounted for between 3 $12 \%$ of the variance in school dropout (Cox and Snell $R^{2}=.03$; Nagelkerke $R^{2}=.12$ ). After controlling for child age, province, and urban versus rural location, higher poverty scores were associated with significantly higher odds of school dropout a year later (Table 4). The association between gender and school dropout was approaching significance $(p=.07)$, with a trend for girls to be at greater risk of school dropout. Additionally, the interaction between poverty and gender was significant. As indicated in Figure 1, at low (1SD below the mean) and mean levels of poverty girls were at elevated risk of school dropout; however, at higher levels of poverty (1SD above the mean) this gender difference was no longer evident and boys were at equally elevated risk of school dropout.

(Table 4 and Figure 1)

\section{Discussion}

Education is an essential tool of welfare, particularly in LMIC where children's wellbeing as adults is strongly dependent on their educational outcomes (Glewwe \& Kremer, 2006). The current study investigated prospective associations between poverty, gender, and school dropout in a large community sample of South African adolescents. We also examined whether associations between gender and school dropout were moderated by poverty.

Overall school dropout rates were approximately 3.5\%. This is consistent with South African data indicating that around $96 \%$ of children and adolescents were enrolled in school (Meny-Gibert \& Russell, 2010). As predicted, after controlling for important socio-demographic confounders (age, province, and urban versus rural location) higher poverty was associated with school drop-out. Additionally, there was a trend towards girls being at elevated risk of school 
Poverty, gender, and school dropout 11

dropout overall $(p=.07)$. These findings are consistent with previous research and data from LMIC (Fleisch et al., 2012; Flisher et al., 2010; Herz \& Sperling, 2004; Orkin et al., 2014;

UNESCO, 2012; World Bank, 2016). However, poverty additionally moderated the association between gender and school dropout. We had initially hypothesized that the impact of poverty on school dropout would be stronger for girls than boys. Unexpectedly, our analysis indicated that although girls were at elevated risk of school dropout overall, at high levels of poverty this gender difference was no longer evident and boys were at equally elevated risk of school dropout.

One potential explanation for this finding may be the distinction between absolute and relative poverty (Foster, 1998). Absolute poverty refers to households living below a minimum standard necessary to sustain subsistence. From this perspective, individuals falling under some fixed absolute threshold are defined as poor. Absolute poverty is a particularly useful indicator for enabling comparisons across geographies and time (Dieltiens \& Meny-Gibert, 2012). However, measures of absolute poverty do not capture variability in the depth and distribution of poverty within communities (Foster, 1998). In contrast, relative poverty is defined with reference to the society in which an individual lives, and explicitly captures variability in the depth and distribution of poverty within communities. Individuals or families are judged to be poor if they are poor in comparison to those around them (Dieltiens \& Meny-Gibert, 2012; Foster, 1998; Noble, Wright, \& Cluver, 2007). Traditionally, relative poverty reflects a psychosocial experience of poverty, in which poverty is not only about material deprivation but also considers how individuals see themselves in relation to others in society and whether individuals believe they can participate fully in society (Dieltiens \& Meny-Gibert, 2012). Although the poverty measure used in the current study did not assess beliefs about societal participation and exclusion, the notion of relative poverty raises the possibility that variability in levels of poverty is important, even within communities experiencing high rates of absolute poverty (and we 
Poverty, gender, and school dropout 12

suggest that capturing variability in the depth of poverty may be conceptually similar to relative poverty within these communities).

The communities we sampled are extremely poor, even given the high absolute rates of poverty in South Africa (Dieltiens \& Meny-Gibert, 2012; Oosthuizen, 2008). On average households were lacking nearly three of the eight basic necessities identified in the South African Social Attitudes Survey as being a basic need for all children and adolescents in South Africa (Pillay et al., 2006). Therefore, a high level of family poverty within these communities represents extreme economic vulnerability. Our data indicate that this extreme economic vulnerability is associated with elevated risk of school dropout and that this is the case for both boys and girls. Additionally, within these generally high poverty communities girls are at increased risk of dropout overall. However, in families experiencing extreme economic vulnerability, girls and boys are at equally elevated risk of dropout. Assessing variability in poverty within communities may enable a more fine-grained understanding of associations between poverty, gender and school dropout that might be masked when an absolute definition of poverty is used. Further research examining gender differences in school dropout at varying levels of poverty could shed additional light on this important issue.

If replicated, the finding that poverty moderates the association between gender and school dropout has important policy implications. International policy makers have placed a strong emphasis on promoting gender equality in education, with the specific objective of breaking cycles of poverty (USAID, 2015). Our finding that overall girls were at greater risk of school dropout strongly supports the importance of global efforts to reduce gender inequality in education. However, the finding that boys were at equally elevated risk of school dropout at high levels of poverty indicates that vulnerable boys should not be neglected in policy and programming decisions. Specifically, in the context of extreme poverty and vulnerability, the focus should be on keeping all adolescents in school. It will be important to identify whether policies to support school retention work similarly or differently across genders. This finding is 
Poverty, gender, and school dropout 13

consistent with a recent call for a broader equity approach to child development in the context of vulnerability, particularly in highly HIV-affected communities (Hensels et al., 2016).

The study has a number of limitations that should be noted. First, although the overall sample was quite large, given the relatively low dropout rates we did not have sufficient participants to examine whether impacts of poverty and gender on school dropout differ across primary and secondary school. This is an important question and should be addressed in future research. Second, participants were sampled from low income areas where the population is predominantly black African. Findings are therefore not necessarily generalizable to other population groups in South Africa. Additionally, as the study was limited to one country, findings may not be representative of other LMIC. Further research is needed to determine the extent to which the South African experience is representative of LMIC more broadly. Third, although the longitudinal design is a strength of the study, the data were limited to two time points. Additional research examining longer-term associations between gender, poverty, and educational outcomes would be beneficial. Finally, although the retention rate was high, some of the most vulnerable children and adolescents were among those unable to be traced and all results should be interpreted with this in mind.

Bearing these limitations in mind, the current study establishes the importance of a nuanced understanding of how poverty and gender impact school dropout. It is essential that we continue to support girls living in poverty to attend school and to close the gender gap in education (United Nations, 2015). However, extreme poverty raises dropout risk for both girls and boys, and vulnerable boys should not be neglected in policies to improve retention in education. 
Acknowledgements:

This study was funded by the UK Economic and Social Research Council, the South African National Research Foundation, the Health Economics and HIV/AIDS Research Division (HEARD) at the University of KwaZulu-Natal, the South African National Department of Social Development, the Claude Leon Foundation, the John Fell Fund, and the Nuffield Foundation. Support was provided to Lucie Cluver by the European Research Council (ERC) under the European Union's Seventh Framework Programme (FP7/2007-2013)/ERC grant agreement $\mathrm{n}^{\circ} 313421$ and the Philip Leverhulme Trust (PLP-2014-095). The authors wish to thank the South African fieldwork teams and all the participants and their families. 
Poverty, gender, and school dropout 15

\section{References}

Anand, S., \& Sen, A. (2000). The income component of the human development index. Journal of Human Development, 1, 83-106.

Barnes, H., \& Wright, G. (2012). Defining child poverty in South Africa using the socially percieved necessities approach. In A. Minujin (Ed.), Global Child Poverty and WellBeing: Measurement, Concepts, Policy and Action. Bristol: The Policy Press.

Battin-Pearson, S., Newcomb, M. D., Abbott, R. D., Hill, K. G., Catalano, R. F., \& Hawkins, D. (2000). Predictors of early high school dropout: A test of five theories. Journal of Educational Psychology, 92, 568-582.

Branson, N., \& Leibbrandt, M. (2013). Educational Attainment and Labour Market Outcomes in South Africa, 1994-2010, OECD Economics Department Working Papers, No. 1022. Paris: OECD Publishing.

Cluver, L., Orkin, M., Boyes, M. E., Sherr, L., Makasi, D., \& Nikelo, J. (2013). Pathways from parental AIDS to child psychological, educational, and sexual risk: Developing an empirically-based interactive theoretical model. Social Science and Medicine, 87, 185193.

Department of Education. (2009). Trends in education macro indicators report: South Africa. Pretoria: Department of Education.

Dieltiens, V., \& Meny-Gibert, S. (2012). In class? Poverty, social exclusion and school access in South Africa. Journal of Education, 55, 127-144.

Dolata, S., Hungi, N., Makuwa, D., Paviot, L., Ross, K., Saito, M., . . Vellien, J. (2010). SACMEQ III Project results: Pupil achievement levels in reading and mathematics. Paris: Southern and Eastern Africa Consortium for Monitoring Educational Quality. Fleisch, B. (2008). Primary education in crisis: Why South African school children underachieve in reading and mathematics. Cape Town: Juta \& Company. 
Poverty, gender, and school dropout 16

Fleisch, B., Shindler, J., \& Perry, H. (2012). Who is out of school? Evidence from the Statistics South Africa Community Survey. International Journal of Educational Development, $32,529-536$.

Fleisch, B., \& Woolman, S. (2004). On the constitutionality of school fees: A reply to Roithmayr. Perspectives in Education, 22, 111-123.

Flisher, A. J., Townsend, L., Chikobvu, P., Lombard, C. J., \& King, G. (2010). Substance use and psychosocial predictors of high school dropout in Cape Town, South Africa. Journal of Research on Adolescence, 20, 237-255.

Foster, J. E. (1998). Absolute versus Relative Poverty. The American Economic Review, 88, $335-341$.

Glewwe, P., \& Kremer, M. (2006). Schools, teachers, and education outcomes in developing countries. In E. Hanushek \& F. Welch (Eds.), Handbook of the Economics of Education (Volume 2) (pp. 945-1017). Oxford: Elsevier.

Gow, J., \& Desmond, C. (2007). The impact of the AIDS epidemic on South Africa's children. In G. A. Cornia (Ed.), AIDS, public policy and child wellbeing (2nd Edition). Florence: UNICEF Innocenti Research Centre.

Hensels, I. S., Sherr, L., Skeen, S., Macedo, A., Roberts, K. J., \& Tomlinson, M. (2016). Do not forget the boys - gender differences in children living in high HIV-affected communities in South Africa and Malawi in a longitudinal, community-based study. AIDS Care, 28 (Suppl 2), 100-109.

Herz, B., \& Sperling, G. B. (2004). What works in girls' education: Evidence and policies from the developing world. New York: Council on Foreign Relations.

Howie, S., Venter, E., Van Staden, S., Zimmerman, L., Long, C., Du Toit, C., . . Archer, E. (2008). PIRLS 2006 Summary Report: South African children's reading literacy achievement. Pretoria: Center for Evaluation and Assessment. 
Klasen, S. (2002). Low schooling for girls, slower growth for all? Cross-country evidence on the effect of gender inequality in education and economic development. The World Bank Economic Review, 16, 345-373.

Lam, D., Ardington, C., \& Leibbrandt, M. (2011). Schooling as a lottery: Racial differences in school advancement in urban South Africa. Journal of Development Economics, 95, 121136.

Lewin, K. M. (2007). Improving access, equity and transitions in education: Creating a research agenda (Create Pathways to Access Research Monograph No 1) Brighton: University of Sussex.

Maharaj, P., Kaufman, C., \& Richter, L. (2000). Children's Schooling in South Africa: Transitions and Tensions in Households and Communities. CSDS Working Paper 30. Durban: University of KwaZulu-Natal.

Meny-Gibert, S., \& Russell, B. (2010). Treading water: Enrolment, delays and completion in South African schools. Access to Education Series, Volume 1. Johannesburg: Social Surveys Africa.

Modisaotsile, B. M. (2012). The failing standard of basic education in South Africa - AISA Policy Brief No. 72. Pretoria: Africa Institute of South Africa.

Nelson Mandela Foundation. (2005). Emerging voices: A report on education in South African rural communities. Cape Town: HSRC Press.

Noble, M., Wright, G., \& Cluver, L. D. (2007). Conceptualising, defining and measuring child poverty in South Africa: an argument for a multidimensional approach. In A. Dawes, R. Bray, \& A. Van Der Merwe (Eds.), Monitoring child well-being: a South African rightsbased approach. Cape Town: HSRC Press.

Oosthuizen, M. (2008). Estimating poverty lines for South Africa. Discussion document, research commissioned by the Department of Social Development. Cape Town: University of Cape Town: Development Policy Research Unit 
Orkin, M., Boyes, M. E., Cluver, L. D., \& Zhang, Y. (2014). Pathways to poor educational outcomes for HIV/AIDS-affected youth in South Africa. AIDS Care, 26, 343-350.

Pillay, U., Roberts, B., \& Rule, S. (2006). South African social attitudes: changing times, diverse voices. Cape Town: HSRC Press.

Sayed, Y., Subrahmanian, R., Soudien, C., Carrim, N., Balgopalan, S., Nekhwevha, F., \& Samuel, M. (2007). Education exclusion and inclusion: Policy and implementation in South Africa and India. London: Department for International Development.

Spaull, N. (2012). Poverty and privilege: Primary school inequality in South Africa Stellenbosch Economic Working Papers 13/12. Stellenbosch: Department of Economics and The Bureau for Economic Research, University of Stellenbosch.

Stacki, S. L., \& Baily, S. (2015). Educating adolescent girls around the globe: Challenges and opportunities. New York: Routledge.

Taylor, N., Muller, J., \& Vinjevold, P. (2003). Getting schools working: Research and systematic school reform in South Africa. Cape Town: Maskew Miller Longman.

UNESCO. (2012). World atlas of gender equality of education. . Paris: UNESCO.

United Nations. (2015). Transforming our world: The 2030 agenda for sustainable development A/RES/70/1: United Nations.

USAID. (2015). Let Girls Learn Fact Sheet. Washington DC: USAID.

van der Berg, S. (2005). Poverty and education. Paris: UNESCO.

Watkins, J. A., Sello, O. M., Cluver, L. D., Kaplan, L., \& Boyes, M. E. (2014). ‘At school I got myself a certificate': HIV/AIDS Orphanhood and secondary education: A qualitative study of risk and protective factors. Global Social Welfare, 1, 111-121.

World Bank. (2016). Reaching girls, transforming lives: Education Global Practice snapshot. Washington, D. C.: World Bank Group. 
Table 1. Sample characteristics at baseline and follow-up assessments, disaggregated by gender

\begin{tabular}{|c|c|c|c|c|c|c|}
\hline & \multicolumn{3}{|c|}{ Baseline $(n=3515)$} & \multicolumn{3}{|c|}{ Follow-up $(n=3401)$} \\
\hline Poverty $(M, S D)$ & $2.66(2.31)$ & $2.76(2.33)$ & .204 & $2.61(2.33)$ & $2.85(2.35)$ & .004 \\
\hline Live in urban area $(n, \%)$ & $789(52 \%)$ & $989(50 \%)$ & -- & $763(52 \%)$ & $957(50 \%)$ & -- \\
\hline Live in rural area $(n, \%)$ & $734(48 \%)$ & $1003(50 \%)$ & .205 & $712(48 \%)$ & $969(50 \%)$ & .238 \\
\hline Mpumlanga $(n, \%)$ & $751(49 \%)$ & $913(46 \%)$ & -- & $746(51 \%)$ & $902(47 \%)$ & -- \\
\hline Western Cape $(n, \%)$ & $772(51 \%)$ & $1079(54 \%)$ & .041 & $729(49 \%)$ & $1024(53 \%)$ & .030 \\
\hline
\end{tabular}

Note: $p$ values are associated with one-way ANOVAs or $\chi^{2}$ tests. Significant $p$ values bolded. 
Table 2. Comparison of children lost and retained at follow-up assessment

\begin{tabular}{lccc}
\hline & $\begin{array}{c}\text { Not Followed-up } \\
(n=114)\end{array}$ & Followed-up \\
& $66(3.3 \%)$ & $1926(96.7 \%)$ & -- \\
\hline Girls $(n, \%)$ & $48(3.2 \%)$ & $1475(96.8 \%)$ & .79 \\
Boys $(n, \%)$ & $13.95(2.24)$ & $13.43(2.15)$ & $\mathbf{. 0 1}$ \\
Age $(M, S D)$ & $4(3.5 \%)$ & $55(1.6 \%)$ & .13 \\
School non-enrolment $(n, \%)$ & $3.63(2.35)$ & $2.68(2.31)$ & $<.001$ \\
Poverty $(M, S D)$ & & & \\
\hline
\end{tabular}

Note: $p$ values associated with one-way ANOVAs or $\chi^{2}$ tests. Significant $p$ values bolded. 
Table 3: Descriptive poverty and educational data for children followed up and enrolled in Grades 1-11 at baseline assessment

\begin{tabular}{|c|c|c|c|c|}
\hline & \multicolumn{2}{|c|}{ Baseline $(n=3319)$} & \multicolumn{2}{|c|}{ Follow-up $(n=3319)$} \\
\hline School Dropout $(n, \%)$ & -- & -- & $39(2.7 \%)$ & $66(3.5 \%)$ \\
\hline Grade $2(n, \%)$ & $17(1 \%)$ & $15(1 \%)$ & $3(<1 \%)$ & $8(<1 \%)$ \\
\hline Grade $3(n, \%)$ & $73(5 \%)$ & $51(3 \%)$ & $25(2 \%)$ & $15(<1 \%)$ \\
\hline Grade $4(n, \%)$ & $147(10 \%)$ & $160(9 \%)$ & $87(6 \%)$ & $61(3 \%)$ \\
\hline Grade $5(n, \%)$ & $204(14 \%)$ & $264(14 \%)$ & $134(9 \%)$ & $166(9 \%)$ \\
\hline Grade $8(n, \%)$ & $227(16 \%)$ & $285(15 \%)$ & $244(17 \%)$ & $281(15 \%)$ \\
\hline Grade $9(n, \%)$ & $154(11 \%)$ & $288(15 \%)$ & $230(16 \%)$ & $308(17 \%)$ \\
\hline Grade $10(n, \%)$ & $84(6 \%)$ & $154(8 \%)$ & $140(10 \%)$ & $253(14 \%)$ \\
\hline
\end{tabular}


Poverty, gender, and school dropout 22

Grade $11(n, \%)$

Grade $12(n, \%)$
$31(2.1 \%)$

$68(4 \%)$

$71(4.9 \%)$

$31(2 \%)$

$--$ 
Table 4: Multivariate associations between poverty, gender, and school dropout adjusting for age, province, and urban versus rural location

\begin{tabular}{lccc}
\hline & $B(S E)$ & Odds Ratio $(95 \% \mathrm{CI})$ & $p$ \\
\hline Constant & $-4.13(.22)$ & .02 & $<.001$ \\
Age & $.83(.11)$ & $2.29(1.83-2.88)$ & $<. \mathbf{0 0 1}$ \\
Province & $-.17(.12)$ & $.84(.67-1.06)$ & .14 \\
Urban/Rural Location & $.08(.10)$ & $1.08(.88-1.32)$ & .46 \\
Poverty & $.70(.17)$ & $2.01(1.45-2.79)$ & $<.001$ \\
Gender & $.44(24)$ & $1.56(.97-2.51)$ & .07 \\
Poverty*Gender & $-.41(.20)$ & $.66(.45-.99)$ & $\mathbf{. 0 4}$ \\
\hline
\end{tabular}

Note: Significant $p$ values bolded 
Poverty, gender, and school dropout 24

\section{$\underline{\text { Figure Caption }}$}

Figure 1: Interaction between gender and poverty in predicting school dropout (adjusting for age, province, and urban vs rural location)

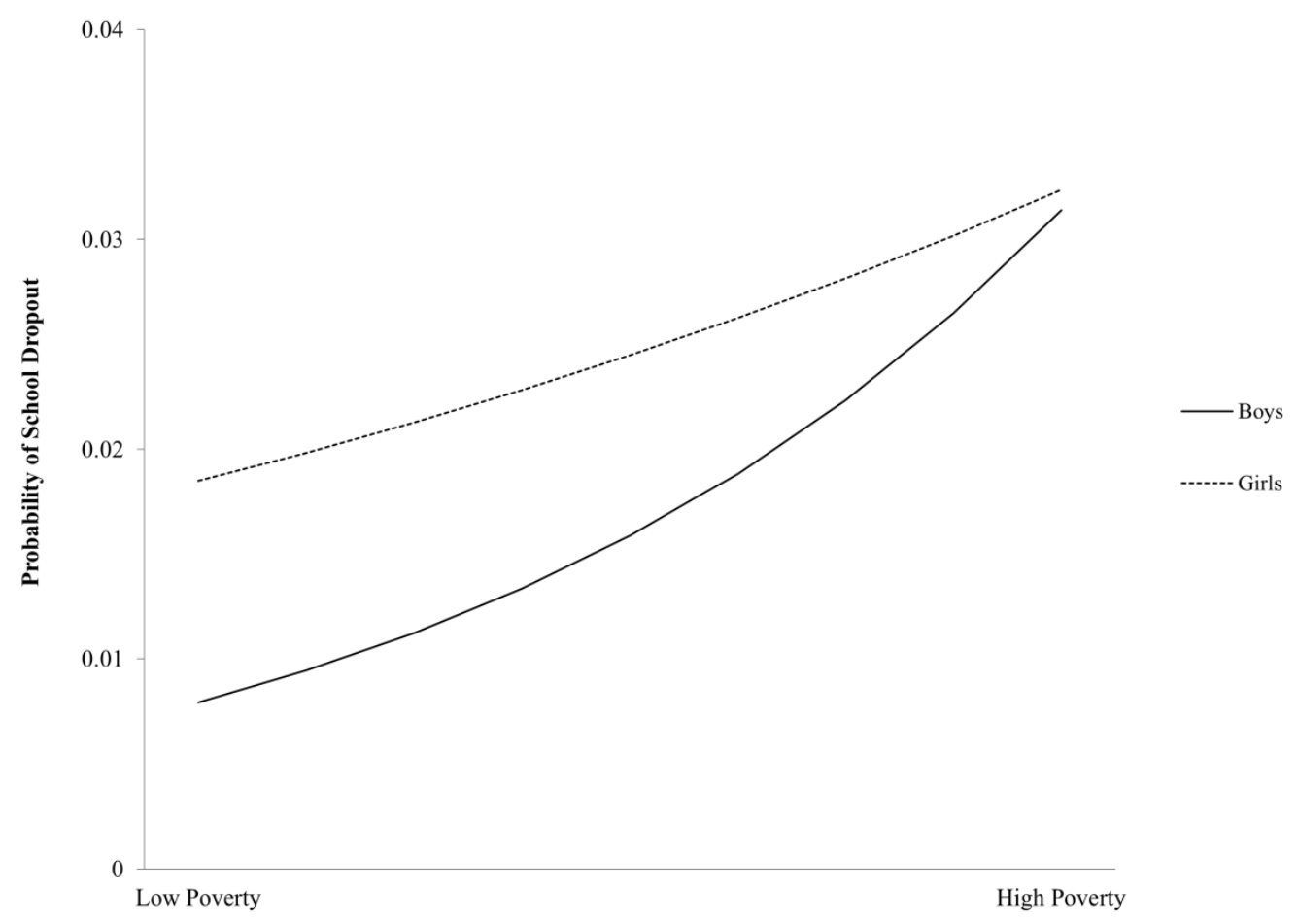

